\title{
Produção de mudas de Ceiba speciosa em diferentes volumes de tubetes utilizando o biossólido como substrato
}

\author{
Seedling production of Ceiba speciosa in different volume of tubes using biosolids as substrate \\ Pedro Lima FilhoI, Paulo Sérgio dos Santos Leles ${ }^{\mathrm{II}}$, Alan Henrique Marques de Abreu ${ }^{\mathrm{III}}$, \\ Eduardo Vinícius da Silva ${ }^{\mathrm{IV}}$, Aline Cássia da Fonseca ${ }^{\mathrm{V}}$
}

\begin{abstract}
Resumo
Um dos problemas encontrados na formação de povoamentos visando à restauração florestal é a qualidade das mudas. O objetivo deste trabalho foi avaliar diferentes volumes de tubetes para a produção de mudas de Ceiba speciosa, utilizando o biossólido como substrato. O experimento constou da fase de produção das mudas e da avaliação do desempenho dessas no campo. Os tratamentos utilizados foram os tubetes de 55, 110, 180 e $280 \mathrm{~cm}^{3}$. Ambas as fases do experimento foram instaladas em delineamento inteiramente casualizado, sendo a fase de viveiro composta por quatro repetições de 12 plantas, e a fase de campo composta por 20 mudas de cada tratamento, com altura e diâmetro mais próximos da média da última avaliação realizada no viveiro. Utilizando-se o biossólido como principal componente do substrato para a produção das mudas de Ceiba speciosa, e para as condições de sítio em que foi implantado o povoamento florestal, recomenda-se o uso do tubete de $110 \mathrm{~cm}^{3}$, pois neste ocorreu crescimento similar ao das plantas nos tubetes de maior volume, resultando em menor volume de substrato, menor área ocupada no viveiro e maior facilidade de transporte e manejo.
\end{abstract}

Palavras-chave: Lodo de esgoto; Qualidade de mudas; Restauração florestal; Paineira

\begin{abstract}
One of the problems encountered in the formation of stands aimed at forest restoration is the quality of the seedlings. The objective of this study was to evaluate the different volumes of tubes for the seedling production of Ceiba speciosa, using biosolids as a substrate. The experiment consisted of the seedlings production stage and evaluation of the performance in the field. The treatments were the tubes of 55,110,180 and $280 \mathrm{~cm}^{3}$. Both phases of this experiment were installed in a completely randomized design, with the stage of seedling production composed by four repetitions of 12 plants, and field stage composed by 20 seedlings from each treatment, with height and diameter closer to the average for the last assessment carried out in the nursery. Using biosolids as the main component of the substrate for the production of Ceiba speciosa seedlings, and for the site conditions where the forest stand was implanted, it is recommended to use the $110 \mathrm{~cm}^{3}$ tube, because in this tube occurred growth similar to plants in the tubes of larger volumes, resulting in lower volume of substrate, smaller area occupied in the seed-plot and greater ease of transport and handling.
\end{abstract}

Keywords: Sewage sludge; Seedlings quality; Forest restoration; Ceiba

\footnotetext{
${ }^{1}$ Engenheiro Florestal, Mestre em Ciências Ambientais e Florestais pelo Programa de Pós-Graduação em Ciências Ambientais e Florestais, Universidade Federal Rural do Rio de Janeiro, BR 465, km 7, CEP 23890-000, Seropédica (RJ), Brasil. limafilhop@ gmail.com (ORCID: 0000-0003-3611-1653)

II Engenheiro Florestal, Dr., Professor Titular do Instituto de Florestas, Universidade Federal Rural do Rio de Janeiro, BR 465, km 7, CEP 23890-000, Seropédica (RJ), Brasil. pleles@ufrrj.br (ORCID: 0000-0002-8393-6095)

III Engenheiro Florestal, Doutor em Ciências Ambientais e Florestais pelo Programa de Pós-Graduação em Ciências Ambientais e Florestais, Universidade Federal Rural do Rio de Janeiro, BR 465, km 7, CEP 23890-000, Seropédica (RJ), Brasil. alanhenriquem@gmail.com (ORCID: 0000-0002-2960-5201)

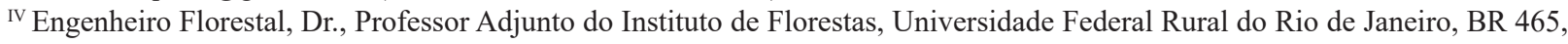
km 7, CEP 23890-000, Seropédica (RJ), Brasil. evsilva@ufrrj.br (ORCID: 0000-0002-1115-0624)

v Engenheira Florestal, Mestre em Ciência Florestal pelo Programa de Pós-Graduação em Ciência Florestal, Universidade Estadual Paulista, Fazenda Lageado, Rua José Barbosa de Barros, 1780, CEP 18610-307, Botucatu (SP), Brasil. aline_cfonseca@, hotmail.com (ORCID: 0000-0002-0998-4304)
} 


\section{Introdução}

Um dos principais problemas encontrados na formação dos povoamentos visando à restauração florestal é a qualidade das mudas. Estas, juntamente com os fatores ambientais e as técnicas silviculturais, são importantes para a redução dos custos e diminuição do tempo de formação do povoamento. Entre as espécies amplamente utilizadas na recomposição florestal de ecossistemas da Mata Atlântica, encontra-se a Ceiba speciosa (A. St.-Hil.) Ravenna (paineira) (RODRIGUES; BRANCALION; ISERNHAGEN, 2009). A paineira, pertencente à família das Malvaceaea, é classificada como pioneira e possui rápido crescimento, além de ser uma espécie que apresenta ampla distribuição geográfica no território brasileiro (CARVALHO, 2004).

A qualidade das mudas aptas para o plantio refere-se à capacidade de resistirem às condições adversas encontradas no campo e produzirem árvores com crescimento desejável (CARNEIRO, 1995; PORTELA; SILVA; PINÃ-RODRIGUES, 2001). Vários fatores afetam a formação das mudas, dentre eles a qualidade das sementes, tipo de recipiente, substrato empregado, adubação e manejo durante o processo de produção (SANTOS et al., 2000; BLAISE et al., 2005; CUNHA et al., 2009; TRAZZI et al., 2012; CALDEIRA et al., 2013b).

A utilização de resíduos orgânicos como substrato para produção de mudas de espécies florestais nativas, geralmente, é uma alternativa viável, visto que, normalmente são ricos em nutrientes e são produzidos em grande quantidade, e sua destinação é um problema para as empresas produtoras (QUINTANA; CARMO; MELO, 2009). Entre estes resíduos encontra-se o biossólido, originário das estações de tratamento do esgoto doméstico, que, normalmente, apresenta alto teor de matéria orgânica, possui quantidades apreciáveis de nutrientes, principalmente $\mathrm{N}$ e $\mathrm{P}$, e pode melhorar as propriedades físicas, químicas e biológicas dos substratos, e ser utilizado como fonte de nutrientes para o crescimento das plantas (BETTIOL; CAMARGO, 2006; BOVI et al., 2006; PADOVANI, 2006; CALDEIRA et al., 2013a; SANTOS, 2013; ABREU et al., 2017b).

Diversos autores (AUGUSTO et al., 2003; CALDEIRA et al., 2008; TRAZZI et al., 2012; CALDEIRA et al., 2013a; GOMES et al., 2013; ABREU, 2014) demonstram ganhos no crescimento e qualidade das mudas florestais nativas quando se utiliza o biossólido como componente do substrato. Dessa forma, este material possui grande potencial, o que pode garantir a boa formação e qualidade para as mudas, além de influenciar diretamente no sucesso dos povoamentos visando à restauração florestal.

No mesmo grau de importância que o substrato empregado, o tipo e as características do recipiente a se utilizar também irão influenciar a qualidade das mudas. O volume do recipiente tem relação direta na quantidade de substrato, no espaço que irá ocupar no viveiro, na mão de obra, no custo final da muda, no transporte e rendimento durante o plantio e, principalmente, na quantidade de insumos utilizados (GOMES et al., 1990; CARNEIRO, 1995; NEVES et al., 2005; VIANA et al., 2008; LISBOA et al., 2012).

Vários estudos, com diferentes espécies para a restauração florestal, mostram que os recipientes maiores, normalmente, são os que proporcionam melhor qualidade às mudas (TEIXEIRA et al., 2005; VIANA et al., 2008; BOMFIM et al., 2009; KELLER et al., 2009). Porém, associar o poder nutricional que a maioria dos biossólidos possuem (BETTIOL; CAMARGO, 2006; BOVI et al., 2006; PADOVANI, 2006; CALDEIRA et al., 2013a; SANTOS, 2013; ABREU et al., 2017b) com a utilização de recipientes com menores dimensões poderá ser uma forma de reduzir os custos na fase de produção, transporte e distribuição em campo, proporcionando a formação de mudas de qualidade, com menor gasto e melhor rendimento na operação de plantio, o que irá diminuir os custos dos reflorestamentos destinados à restauração florestal.

O objetivo deste trabalho foi avaliar diferentes volumes de tubetes na produção de mudas de Ceiba speciosa (A. St.- Hil.) Ravenna (paineira), utilizando o biossólido como substrato. 


\section{Material e métodos}

O presente estudo foi realizado em duas fases, sendo a primeira referente à produção das mudas realizada no viveiro florestal da Universidade Federal Rural do Rio de Janeiro (UFRRJ), no período de junho a outubro de 2013. A segunda fase consistiu no plantio, condução e avaliação das plantas oriundas dos diferentes volumes de tubetes, em uma propriedade particular, de outubro de 2013 a maio de 2014, utilizando-se mudas de Ceiba speciosa (A. St.- Hil.) Ravenna (paineira).

Fase de viveiro

$\mathrm{O}$ experimento foi instalado em delineamento inteiramente casualizado, composto por quatro tratamentos, com quatro repetições de 12 plantas, totalizando 48 indivíduos por tratamento. Os tratamentos consistiram em tubetes de $55 \mathrm{~cm}^{3}, 110 \mathrm{~cm}^{3}, 180 \mathrm{~cm}^{3}$ e $280 \mathrm{~cm}^{3}$ de volume.

O substrato foi composto por $80 \%$ de biossólido e $20 \%$ de fibra de coco. A fibra de coco, por ser material inerte, foi utilizada para proporcionar maior agregação no substrato. O biossólido utilizado foi caracterizado por Abreu (2014) (Tabela 1).

Tabela 1 - Análise química do biossólido utilizado como componente do substrato para a produção de mudas florestais da Mata Atlântica.

Table 1 - Chemical analysis of biosolids used as a component of the substrate for the forest seedlings production of Atlantic Forest.

\begin{tabular}{|c|c|c|}
\hline Substância & Unidade & Concentração \\
\hline Carbono orgânico & $\mathrm{mg} \mathrm{kg}^{-1}$ & 2.870 \\
\hline Fósforo total & $\mathrm{mg} \mathrm{kg}^{-1}$ & 6.161 \\
\hline Nitrogênio Kjeldahl & $\mathrm{mg} \mathrm{kg}^{-1}$ & 33.497 \\
\hline Nitrogênio amoniacal & $\mathrm{mg} \mathrm{kg}^{-1}$ & 208 \\
\hline Nitrito & $\mathrm{mg} \mathrm{N} \mathrm{kg}{ }^{-1}$ & 17,2 \\
\hline Nitrato & $\mathrm{mg} \mathrm{N} \mathrm{kg}{ }^{-1}$ & 5.318 \\
\hline Nitrogênio total & $\mathrm{mg} \mathrm{kg}{ }^{-1}$ & 38.832 \\
\hline Potássio total & $\mathrm{mg} \mathrm{kg}^{-1}$ & 4.995 \\
\hline Sódio total & $\mathrm{mg} \mathrm{kg}^{-1}$ & 1.591 \\
\hline Enxofre total & $\mathrm{mg} \mathrm{kg}^{-1}$ & 11.933 \\
\hline Cálcio total & $\mathrm{mg} \mathrm{kg}^{-1}$ & 2.361 \\
\hline Magnésio total & $\mathrm{mg} \mathrm{kg}^{-1}$ & 145 \\
\hline Sólidos totais & $\%$ & 74,29 \\
\hline Sólidos voláteis & $\%$ & 24,29 \\
\hline Umidade & $\%$ & 25,71 \\
\hline pH em água (1:10) & - & 5,45 \\
\hline
\end{tabular}

As sementes foram provenientes de 12 árvores de um fragmento de Mata Atlântica localizado no município de Além Paraíba - MG, e semeadas diretamente nos recipientes, colocando-se de 2 a 4 sementes por embalagem. Durante todo o período de produção, as mudas permaneceram em bandejas de chão e a pleno sol. Após a emergência das plântulas, foi realizado desbaste, deixando sempre a planta de maior tamanho e mais central. A irrigação das mudas era realizada duas vezes ao dia, em períodos de cinco minutos. 
Quando as mudas estavam com altura média em torno de $15 \mathrm{~cm}$ foi realizado o reespaçamento com alternância dos tubetes nas células das bandejas, ocupando $50 \%$ das células.

Para a avaliação dos efeitos dos diferentes recipientes, mensuraram-se a altura $(\mathrm{H})$ e o diâmetro do coleto (DC) das mudas com régua graduada e paquímetro, respectivamente. Esta atividade foi repetida a cada 21 dias, para o acompanhamento do crescimento, ao longo do tempo. O início das mensurações foi 30 dias após a semeadura e o término aos 93 dias (idade em que as mudas estavam em condições de serem levadas para o campo), totalizando quatro épocas de medições.

Após as últimas medições e análise prévia dos dados, quatro mudas mais próximas da média de cada tratamento e repetição foram selecionadas para a determinação da matéria seca da parte aérea (MSPA), matéria seca do sistema radicular (MSR) e matéria seca total (MST). As mudas selecionadas foram cortadas, separadas parte aérea do sistema radicular e acondicionadas em sacos de papel, em seguida, foram levadas para estufa a $65^{\circ} \mathrm{C}$ até atingir peso constante. A partir dos dados coletados, calculou-se o Índice de Qualidade de Dickson (IQD), segundo Dickson et al. (1960), por meio da equação a seguir:

$$
\mathrm{IQD}=\frac{\mathrm{MST}_{(\mathrm{g})}}{\mathrm{H}_{(\mathrm{cm})} / \mathrm{DC}_{(\mathrm{mm})}+\mathrm{MSPA}_{(\mathrm{g})} / \mathrm{MSR}_{(\mathrm{g})}}
$$

Após tabulados, com os dados das diferentes épocas de avaliação, foram construídos gráficos de crescimento, com os valores médios, em altura e diâmetro do coleto para as plantas dos diferentes tratamentos. Os dados da última medição, juntamente com os valores de peso seco (MSPA e MSR) e IQD foram submetidos à análise de variância, e quando observadas diferenças significativas ao teste de Tukey $(\mathrm{P}>0,95)$.

Fase de campo

A fase de campo foi realizada, durante seis meses, em uma área que estava sendo reflorestada em uma propriedade particular no município de Bom Jardim - RJ. O plantio ocorreu em outubro de 2013.

O clima da região, segundo a classificação de Köppen, é do tipo Aw - tropical chuvoso com inverno seco e verão chuvoso (BRASIL, 1980).

$\mathrm{O}$ experimento foi implantado em área anteriormente ocupada por pastagem, de espécies pertencentes ao gênero Urochloa spp. O solo foi classificado, com abertura de perfil até 1,2 metros, em Latossolo Vermelho Amarelo distrófico, de textura argiloarenosa. A área com o experimento encontrase no terço médio de uma encosta.

Como preparo do solo, as covas foram marcadas em curvas de nível, obedecendo ao espaçamento de 2,5 x 1,8 m. Em seguida, foi aplicado herbicida à base de glifosato em área total (dosagem de 4,0 $\left.\mathrm{L} \cdot \mathrm{ha}^{-1}\right)$. Após aproximadamente 20 dias, as covas foram abertas com a dimensão de $30 \times 30 \times 30 \mathrm{~cm}$.

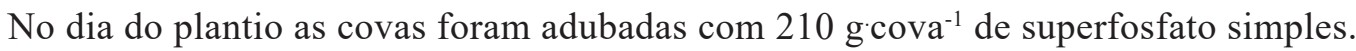

As mudas utilizadas no plantio foram as 20 plantas com altura e diâmetro mais próximos da média da última avaliação realizada no viveiro para cada tratamento. O delineamento utilizado foi o inteiramente casualizado, sendo cada muda correspondente a uma repetição de cada tratamento.

Os tratos culturais envolveram controle das formigas cortadeiras (antes, durante e até cinco meses após o plantio) e controle das plantas daninhas, com coroamento e roçada em janeiro, março e maio de 2014, de modo a manter a área sempre limpa e minimizar os efeitos da competição com outras plantas.

Com base em dados da estação meteorológica do Município de Cordeiro - RJ (INSTITUTO NACIONAL DE METEOROLOGIA, 2014), estação mais próxima da área experimental, na Figura 1 são apresentados os valores de precipitação total e médios de temperatura máxima quinzenal do período do experimento. 
Figura 1 - Precipitação total (barras) e temperatura média (linha), por quinzena, de outubro de 2013 a março de 2014. Fonte: Instituto Nacional de Meteorologia (2014). Números sobre as barras indicam número de dias com precipitação na quinzena.

Figure 1 - Total precipitation (bars) and average temperature (line), by fortnight, from October 2013 to March 2014. Source: Instituto Nacional de Meteorologia (2014). Numbers over the bars indicate the numbers of days with precipitation in the fortnight.

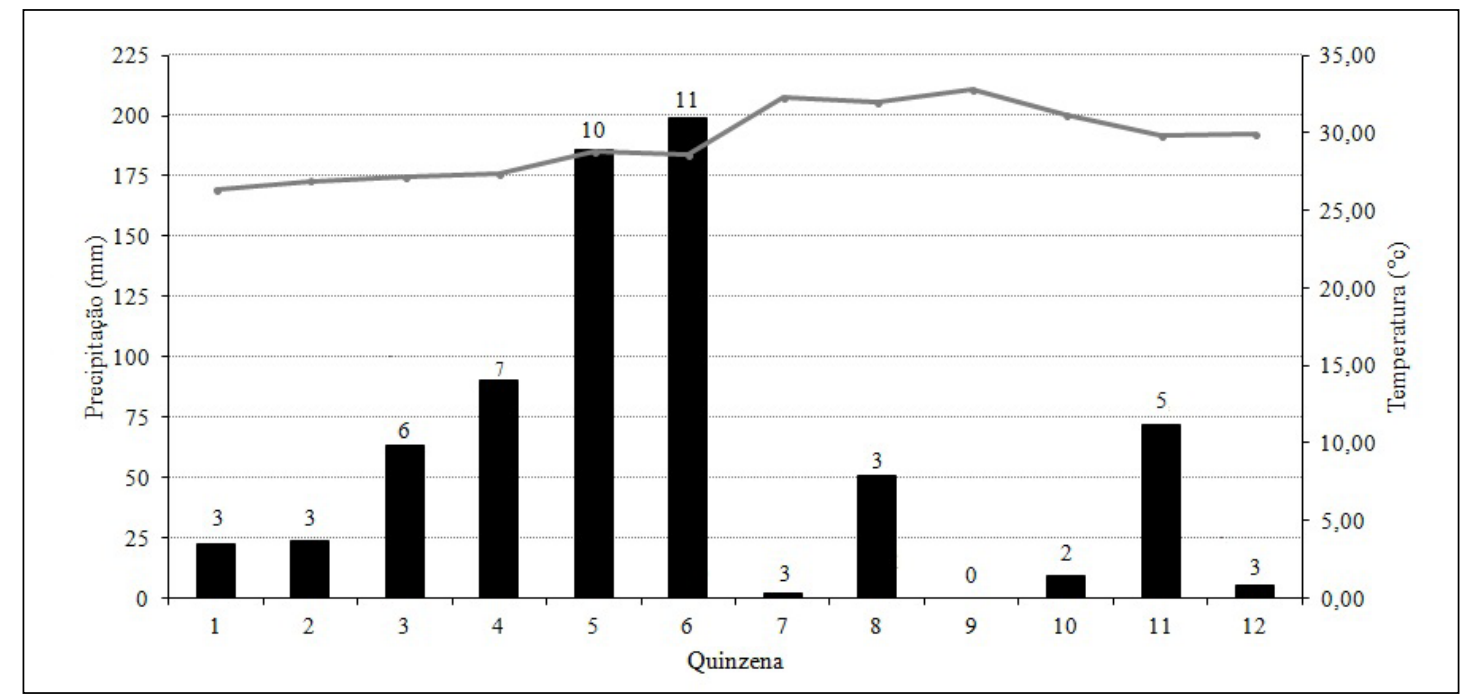

A fim de comparar o comportamento no campo, aos seis meses após o plantio, avaliaram-se a sobrevivência e o crescimento em altura e em diâmetro ao nível do solo.

Os dados de crescimento foram submetidos à análise de variância e constatando diferenças significativas, ao teste de Tukey $(\mathrm{P}>0,95)$.

\section{Resultados e discussão}

Fase de viveiro

Observa-se que, de maneira geral, houve tendência de maior crescimento das mudas nos tubetes de $280 \mathrm{~cm}^{3}$ e menor crescimento nos tubetes de $55 \mathrm{~cm}^{3}$ (Figura 2). Tal fato é confirmado com as médias da última medição, em que as mudas dos tubetes de maior volume apresentaram altura e diâmetro do coleto superior em relação às produzidas em $55 \mathrm{~cm}^{3}$ (Tabela 2).

Figura 2 - Crescimento de Ceiba speciosa ao longo do tempo, em quatro volumes de tubetes.

Figure 2 - Growth of Ceiba speciosa over time in four volumes of tubes.

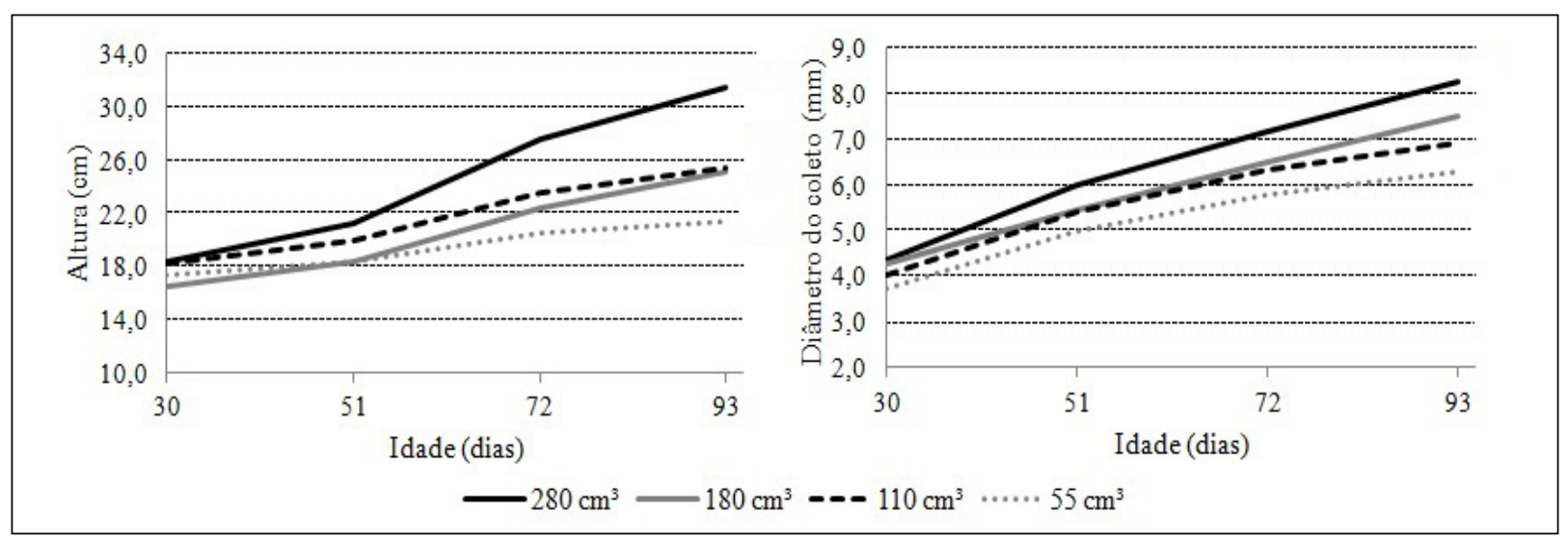




\section{Tabela 2 - Médias das variáveis de crescimento de mudas de Ceiba speciosa produzidas em diferentes volumes de tubetes, aos 93 dias após a semeadura.}

Table 2 - Averages of growth variables of Ceiba speciosa seedlings produced in different volumes of tubes, at 93 days after sowing.

\begin{tabular}{lcccccccccc}
\hline \multirow{2}{*}{$\begin{array}{c}\text { Volume dos } \\
\text { tubetes }\left(\mathrm{cm}^{3}\right)\end{array}$} & \multicolumn{2}{c}{ Altura (H) } & \multicolumn{2}{c}{ Diâmetro (DC) } & \multicolumn{2}{c}{ Parte Aérea (MSPA) } & \multicolumn{2}{c}{ Raízes (MSR) } & \multicolumn{2}{c}{ IQD } \\
\hline 280 & $\mathrm{~cm}$ & $\mathrm{CV}$ & $\mathrm{mm}$ & $\mathrm{CV}$ & g.planta $^{-1}$ & $\mathrm{CV}$ & gplanta $^{-1}$ & $\mathrm{CV}$ & - & $\mathrm{CV}$ \\
180 & $31,4 \mathrm{a}$ & 14,1 & $8,3 \mathrm{a}$ & 9,9 & $19,4 \mathrm{a}$ & 4,6 & $14,0 \mathrm{a}$ & 8,4 & $1,6 \mathrm{a}$ & 8,5 \\
110 & $25,1 \mathrm{~b}$ & 15,5 & $7,5 \mathrm{~b}$ & 9,6 & $14,9 \mathrm{~b}$ & 2,6 & $10,3 \mathrm{~b}$ & 5,3 & $1,3 \mathrm{ab}$ & 11,3 \\
55 & $25,5 \mathrm{~b}$ & 13,3 & $6,9 \mathrm{c}$ & 8,6 & $12,9 \mathrm{c}$ & 2,3 & $9,4 \mathrm{bc}$ & 4,3 & $1,1 \mathrm{bc}$ & 9,6 \\
& $21,3 \mathrm{c}$ & 15 & $6,3 \mathrm{~d}$ & 9,2 & $10,8 \mathrm{~d}$ & 3,6 & $8,9 \mathrm{c}$ & 1,3 & $1,1 \mathrm{c}$ & 8,2 \\
\hline
\end{tabular}

Em que: IQD = Índice de Qualidade de Dickson. Médias seguidas pela mesma letra na coluna não diferem estatisticamente ao teste de Tukey $(\mathrm{P} \geq 0,95) ; \mathrm{CV}=$ Coeficiente de variação (\%).

Este comportamento provavelmente ocorreu devido ao maior volume de substrato e, com isso, maior disponibilidade de nutrientes e de matéria orgânica, evidenciado pelo crescimento intermediário nos tubetes de 180 e $110 \mathrm{~cm}^{3}$. Segundo Gonçalves (1995), substratos com características similares ao biossólido são de fundamental importância para o crescimento de espécies florestais, em que mudas produzidas em substratos com maior quantidade de nutrientes, normalmente, também terão maior acúmulo nutricional nos componentes das plantas (GONÇALVES et al., 2012; ABREU, 2014), e assim com maiores chances de sobrevivência após o plantio no campo.

Na primeira medição, observa-se que a diferença entre os tratamentos é menos expressiva. No entanto, na terceira mensuração (72 dias após semeadura) as tendências de diferenças em altura e diâmetro do coleto são mais perceptíveis (Figura 2). No início, provavelmente, todos os recipientes continham substrato e espaço suficiente para suprir a demanda de nutrientes e para o crescimento inicial do sistema radicular e da parte aérea. Porém, com o aumento da idade e conforme o crescimento das mudas, os tubetes menores ficaram limitados para manter o ritmo de crescimento igual aos tubetes de maiores dimensões, acarretando mudas com diâmetro do coleto e altura inferiores, o que pode ter ocasionado os resultados encontrados.

É possível inferir sobre o tempo de formação das mudas sendo influenciado pelo volume do tubete (Figura 2), aquelas produzidas nos tubetes de maiores dimensões obtiveram crescimento mais acelerado, necessitando de menor tempo para a formação. Desse modo, desde que passada pelo processo de rustificação, estes resultados demonstram que existe a possibilidade de diminuição dos custos de formação de mudas para o viveirista, pois, Lisboa et al. (2012) mencionam que a restrição do crescimento radicular, imposta pelo reduzido volume e pelas paredes dos recipientes menores reduzem alguns parâmetros importantes da qualidade das mudas, como altura e área foliar, o que reduzirá o crescimento e a produção de biomassa, implicando em aumento do número de intervenções no ciclo de produção (CUNHA et al., 2005; VIANA et al., 2008).

Pelos valores das últimas medições, as mudas produzidas nos tubetes de 280 e $180 \mathrm{~cm}^{3}$ ainda estão em pleno crescimento, tanto em altura como em diâmetro, enquanto nos menores recipientes, principalmente nos de $55 \mathrm{~cm}^{3}$, já se observa uma tendência de estabilização, evidenciando a falta de espaço e provavelmente de nutrientes (Figura 2). Um dos maiores problemas encontrados nos viveiros florestais de espécies nativas é o fato da muda ter que esperar as melhores épocas de plantio, acarretando em maior tempo de saída (RIO DE JANEIRO, 2010), o que pode provocar problemas no sistema radicular, como a redução da atividade fisiológica, deformações e necrose de raízes, pela falta de espaço e nutrientes quando se utilizam recipientes menores (LAMHAMEDI et al., 1998; LOPES; AMARAL; NOVAES, 2014).

Apesar do tubete de $55 \mathrm{~cm}^{3}$ ocupar menor espaço no viveiro, para a produção de mudas neste recipiente a necessidade de intervenções será constante, pois o volume de substrato contido não suprirá as demandas nutricionais da planta em comparação aos tubetes maiores, mesmo quando se utilizaram substratos com alta percentagem de biossólido, que é rico em nutrientes (Tabela 1), sendo necessária a aplicação de adubações de cobertura. 
Com os dados de altura e de diâmetro do coleto da última avaliação, juntamente com os valores de matéria seca e índice de qualidade (Tabela 2), constata-se que, de modo geral, as mudas produzidas no tubete de $55 \mathrm{~cm}^{3}$ foram significativamente inferiores às demais. Como o substrato utilizado nos diferentes tubetes foi o mesmo e, conforme discutido anteriormente, as embalagens de maior volume possuem maior quantidade de substrato, por consequência, maior disponibilidade de nutrientes e matéria orgânica, além de menor restrição do sistema radicular (LAMHAMEDI et al., 1998; CUNHA et al., 2005; VIANA et al., 2008; LISBOA et al., 2012) podem ter ocasionado este resultado. Dessa forma, mesmo o biossólido sendo um substrato rico em nutrientes (Tabela 1), a quantidade do mesmo e o espaço nos tubetes de $55 \mathrm{~cm}^{3} n a \tilde{o}$ foi capaz de suprir a demanda da espécie em questão em comparação aos recipientes de maior volume.

Resultado similar a este trabalho foi encontrado por Keller et al. (2009), em estudo com Inga marginata, Jacaranda puberula e Zeyheria tuberculosa produzidas em substrato formado pela mistura de composto orgânico, moinha de carvão e solo argiloso na proporção $3: 1: 1$, utilizando diferentes tipos de embalagens, nas quais o recipiente de menor volume foi o que proporcionou menores taxas de crescimento das mudas. Bomfim et al. (2009), em estudo com Pterogyne nitens produzida com substrato comercial, também mostraram que as mudas nos recipientes de maiores dimensões apresentaram maior crescimento, sendo o tubete de $50 \mathrm{~cm}^{3}$ o que apresentou resultados inferiores.

Ferraz e Engel (2011), estudando três espécies nativas de diferentes estágios ecológicos (Hymenaea coubaril, Tabebuia chrysotricha e Parapiptadenia rigida), verificaram que as mudas produzidas com substrato comercial orgânico no tubete de $300 \mathrm{~cm}^{3}$ (maior recipiente avaliado) foram as que obtiveram maior crescimento, possibilitando reduzir o tempo de produção em até 70 dias. Viana et al. (2008), em estudo com Bauhinia forficata e Teixeira et al. (2005) avaliando Jacaranda micrantha e Triplaris americana, também mostraram efeitos similares ao do presente estudo no crescimento das mudas dessas espécies florestais em diferentes tamanhos de recipientes.

O estudo da biomassa radicular é importante, pois mudas que apresentam maiores valores de biomassa radicial tendem a obter um melhor desempenho após o plantio, por possuírem maior volume de raízes para absorção de água e nutrientes, além da facilidade de sustentação (CARNEIRO, 1995; DAVIDE; SILVA, 2008; BOMFIM et al., 2009). Sistema radicular reduzido resulta em plantas estressadas hidricamente, por não absorverem água suficiente para balancear as perdas pela transpiração (CARNEIRO, 1995; GONÇALVES et al., 2000). Também é importante que haja raízes finas novas, as quais assegurarão o pronto crescimento radicular no campo, agilizando a adaptação da muda ao ambiente (CARNEIRO, 1995; GONÇALVES et al., 2000; ZONTA et al., 2006).

O índice de qualidade de Dickson também foi influenciado pelo volume dos tubetes, nos tubetes menores, os valores encontrados foram inferiores (Tabela 2). No índice de qualidade de Dickson (IQD) é considerado o vigor e o equilíbrio da distribuição da biomassa na muda. Ele pondera os resultados de muitas variáveis, como altura, diâmetro de coleto, matéria seca da parte aérea e de raízes e a relação entre estas (DICKSON; LEAF; HOSNER, 1960; GOMES et al., 2002; BINOTTO et al., 2010). O tubete de 280 $\mathrm{cm}^{3}$ foi o que resultou em melhor IQD, confirmando a influência do volume dos recipientes na produção de mudas florestais, utilizando o biossólido como substrato (Tabela 2).

A ausência de diferenças significativas entre o tratamento de $180 \mathrm{~cm}^{3}$ e $110 \mathrm{~cm}^{3}$ (Tabela 2), para o IQD, pode ser explicada, pois, na idade avaliada, o biossólido presente no substrato, provavelmente, conseguiu suprir as demandas nutricionais da espécie, nestes dois tratamentos. Outro fator para a ausência de diferenças significativas nestes tratamentos é que o tubete de $110 \mathrm{~cm}^{3}$ possui maior comprimento que o tubete de $180 \mathrm{~cm}^{3}$ e, segundo Gomes et al. (1990), em geral a altura da embalagem é mais importante do que o seu diâmetro e volume para o crescimento de mudas de várias espécies florestais, visto que a maior parte destas apresentam crescimento radicular pivotante (CARVALHO, 2004), sendo beneficiado pelo maior comprimento do recipiente.

Resultado semelhante ao deste trabalho foi encontrado por Santos et al. (2000) em estudo com Cryptomeria japonica, aos 111 dias de idade, em que plantas produzidas em substrato formado por proporções iguais de solo e vermiculita, os tubetes de $120 \mathrm{~cm}^{3}$ apresentaram crescimento similar as produzidas no tubete $240 \mathrm{~cm}^{3}$. Nicoloso et al. (2000), em estudo com Apuleia leiocarpa e Maytenus ilicifolia, encontraram que as embalagens maiores ofereceram melhores condições para o crescimento das mudas, sendo a arquitetura do recipiente e o substrato os fatores mais determinantes para a diferença entre os tratamentos.

Ci. Fl., Santa Maria, v. 29, n. 1, p. 27-39, jan./mar., 2019 
Diversos autores (CARNEIRO, 1995; MEXAL et al., 2002; MALAVASI; MALAVASI, 2006) mencionam que no processo de produção de mudas é necessário atentar para o tamanho e volume de recipiente a se utilizar. Do mesmo modo, Cunha et al. (2005) relatam que maiores tubetes oferecem melhores condições para o crescimento das mudas, contudo, eles somente devem ser utilizados para espécies que apresentem crescimento lento, necessitando de maior permanência no viveiro, ou quando se desejam mudas mais desenvolvidas, como para a arborização urbana. Segundo estes autores, embalagens maiores podem tornar o processo de produção das mudas mais oneroso, pelo maior volume de substrato e maior espaço no viveiro. Outro fator importante que deve ser levado em consideração na escolha do recipiente é o custo do transporte do viveiro até a área de plantio (quantidade de mudas por frete) e o rendimento de distribuição das mudas no momento do plantio, devido ao peso e volume dos recipientes, principalmente quando a área a ser restaurada se encontra em locais de difícil acesso e em terrenos declivosos.

\section{Fase de campo}

Para as mudas de Ceiba speciosa oriundas dos tubetes de $110 \mathrm{~cm}^{3}, 180 \mathrm{~cm}^{3}$ e $280 \mathrm{~cm}^{3}$, a sobrevivência das plantas, aos seis meses após o plantio, foi de 90,95 e $90 \%$, respectivamente. O lote de plantas originárias de mudas produzidas no tubete de $55 \mathrm{~cm}^{3}$ apresentou valor igual a $70 \%$. Isto provavelmente ocorreu devido à qualidade inferior das mudas produzidas nos tubetes de $55 \mathrm{~cm}^{3}$ (Tabela 2) aliado à pouca chuva nas primeiras quinzenas após o plantio (Figura 1). Segundo Rodrigues, Brancalion e Isernhagen (2009) em reflorestamentos com espécies florestais nativas da Mata Atlântica, quando a sobrevivência das plantas é inferior a $90 \%$ se faz necessário o replantio, sendo esta uma atividade que aumenta os custos da formação dos povoamentos para a restauração florestal (LELES; OLIVEIRA NETO; ALONSO, 2015).

Apesar do tubete de $55 \mathrm{~cm}^{3}$ proporcionar economia em espaço e substrato no viveiro, menor peso e custo do transporte do viveiro para campo e facilidade na distribuição das mudas, de modo geral, a utilização deste recipiente não é recomendada para a produção de mudas de paineira, pois apresentou a menor sobrevivência das mudas em campo, mesmo a Ceiba speciosa sendo uma espécie de estágio sucessional pioneiro e de rápido crescimento em campo (LORENZI, 2014). Dessa forma, a economia gerada no viveiro e pré-plantio poderá ser perdida nas atividades de replantio, elevando os custos da restauração florestal (RODRIGUES; BRANCALION; ISERNHAGEN, 2009; LELES; OLIVEIRA NETO; ALONSO, 2015).

Nos tubetes maiores, a quantidade de biossólido também é maior, o que propicia maior disponibilidade de nutrientes e melhor nutrição das plantas, repercutindo diretamente na sobrevivência das mudas após o plantio. Segundo Cunha et al. (2009), o estado nutricional das plantas determinará a quantidade de carboidratos, auxinas, entre outros metabólicos fundamentais para a formação radicular e velocidade com que esta ocorre, favorecendo a sobrevivência em campo.

Um estudo avaliando a sobrevivência e crescimento de Pinus taeda em diferentes recipientes foi desenvolvido por Novaes et al. (2002), em que os recipientes de maior volume foram os que apresentaram maior sobrevivência (entre 97 \% e 99 \%) e crescimento em altura e diâmetro de coleto aos 24 meses após o plantio. Estudos com Schinus terebinthifolius (NOBREGA et al., 2007), Schinus terebinthifolius e Handroanthus heptaphyllus (ABREU et al., 2017a), também mostraram que a maior quantidade de biossólido favorece o crescimento das mudas no viveiro, o que de modo geral proporcionou o aumento da taxa sobrevivência após o plantio no campo.

O crescimento médio em altura e em diâmetro de coleto das plantas de Ceiba speciosa, oriundas das mudas produzidas nos quatro volumes de tubetes, aos seis meses após o plantio, estão apresentados na Figura 3. Observa-se que o volume dos tubetes em que as mudas foram produzidas interferiu no crescimento das plantas (Figura 3). Segundo Neves et al. (2005), o volume do recipiente, normalmente, interfere na distribuição do sistema radicular, o que influenciará na sobrevivência e crescimento inicial em campo. 
Figura 3 - Crescimento no campo das mudas de Ceiba speciosa produzidas em quatro volumes de tubetes aos seis meses após o plantio (Bom Jardim - RJ). Em cada gráfico, médias seguidas pela mesma letra não diferem entre si pelo teste de Tukey $(P \geq 0,95)$.

Figure 3 - Growth in the field of Ceiba speciosa seedlings produced in four volumes of tubes at six months after planting (Bom Jardim - RJ). In each graph, averages followed by the same letter do not differ by Tukey test $(\mathrm{P} \geq 0.95)$.

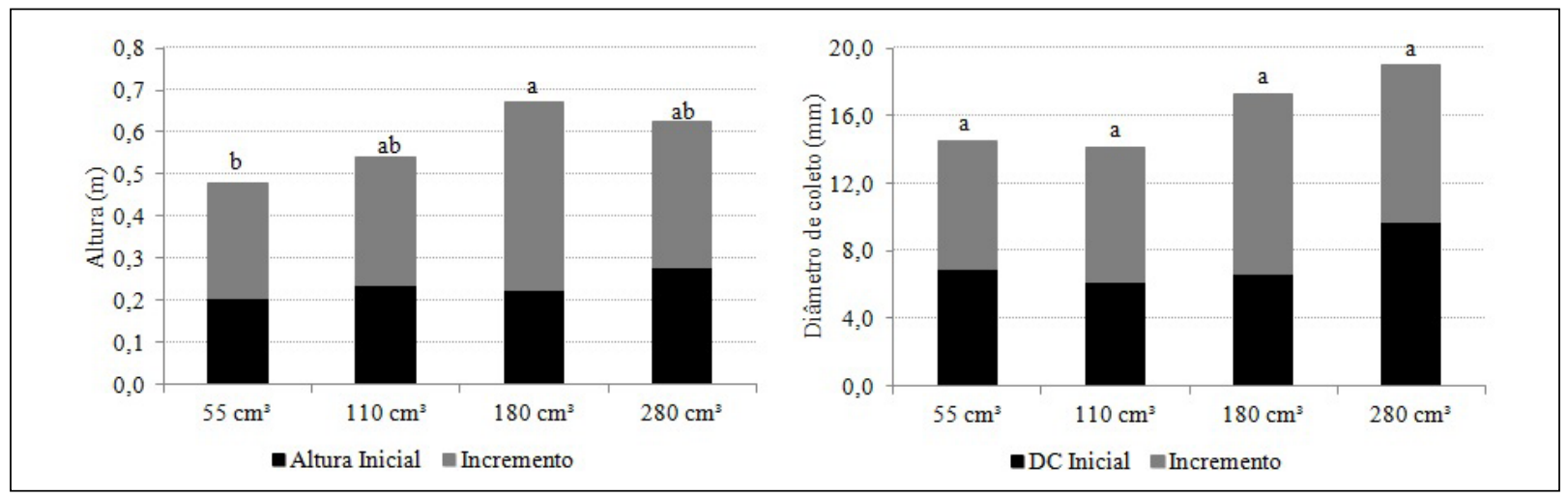

As mudas de Ceiba speciosa obtiveram melhor crescimento quando produzidas em tubetes de $280 \mathrm{~cm}^{3}$ (Figura 2 e Tabela 2) na fase de viveiro, no entanto, esta diferença não foi observada no campo, aos seis meses após o plantio (Figura 3). Este resultado pode ter sido ocasionado devido às mudas que são produzidas em condições de restrição do crescimento radicular, como as dos tubetes com menores volumes, passam na fase de viveiro por processos de rustificação mais severos que as mudas produzidas em recipientes com maiores volumes (ABREU et al., 2015), em que, segundo José, Davide e Oliveira (2005), estes processos de rustificação podem propiciar o desenvolvimento de mecanismos de tolerância às condições de campo, fazendo com que as diferenças no crescimento das mudas produzidas em diferentes tubetes tendenciem a desaparecer com o tempo.

Neste trabalho, possivelmente, foi isto que ocorreu, pois, o incremento em altura e diâmetro de coleto no tubete de $180 \mathrm{~cm}^{3}$ obteve a tendência de ser maior que no recipiente de maior volume. Cabreira et al. (2017) também estudando o crescimento de mudas de Ceiba speciosa, Peltophorum dubium e Lafoensia pacari, utilizando o biossólido como substrato, não identificaram diferenças significativas no crescimento das plantas na fase de campo, mesmo estas sendo plantadas com tamanhos diferentes, aos 150 dias após o plantio. Pezzutti e Caldato (2011), em estudo com mudas de Pinus taeda produzidas em recipientes e expedidas para campo com diferentes tamanhos de diâmetro de coleto, não obtiveram diferenças significativas em sobrevivência e crescimento aos 4 anos de idade. Estes autores explicam que quando se aplicam técnicas adequadas na produção de mudas no viveiro, mesmo que estas apresentem diferentes tamanhos no momento do plantio, porém, sem deficiências, em sítios de boa qualidade, o crescimento tende a ser similar no decorrer do tempo.

Gasparin et al. (2014), em estudo com Cabralea canjarana, também verificaram que aos 180 dias após o plantio não houve diferenças significativas das plantas em diâmetro de coleto, originárias de mudas produzidas em tubetes de 110 e $280 \mathrm{~cm}^{3}$, porém, na avaliação de um ano, houve diferenças em favor das plantas oriundas dos tubetes $280 \mathrm{~cm}^{3}$. Stuepp et al. (2017), trabalhando com mudas de Piptocarpha angustifólia provenientes de miniestaquia com diferentes alturas e diâmetro de coleto, também não encontraram diferenças significativas no crescimento, e que essas variáveis se mantiveram constantes até os 24 meses, independentemente da altura de expedição das mudas.

A diferença após o plantio mais evidente ocorreu no tubete de $55 \mathrm{~cm}^{3}$ em relação aos outros tratamentos, no qual se apresentaram valores de altura aquém dos encontrados nas embalagens maiores (Figura 3). Freitas et al. (2008), em um estudo com clones de Eucalyptus grandis e E. saligna, mostraram que as plantas originárias de mudas de recipientes de maior volume obtiveram maiores valores de altura, diâmetro e biomassa de raízes aos 180 dias após plantio, sendo que o ganho na produção de lenho foi até $80 \%$ maior que nas plantas oriundas de tubetes de $50 \mathrm{~cm}^{3}$. 
Este resultado já era esperado, uma vez que, na fase de viveiro, as mudas oriundas do tubete de 55 $\mathrm{cm}^{3}$ apresentaram menor diâmetro de coleto (Tabela 2), pois, segundo Mexal et al. (2002), em estudo com Swietenia macrophylla e Cedrela odorata, esta variável normalmente possui alta correlação com a taxa de sobrevivência e crescimento em campo, em que os maiores diâmetros também tendem a proporcionar maior sobrevivência e crescimento pós-plantio (RITCHIE et al., 2010). Lopes, Amaral e Novaes (2014), em estudo com três espécies diferentes de eucalipto (Eucalyptus urophylla, E. camaldulensis e Corymbia citriodora), também explicam que recipientes de parede rígida e pequenas dimensões, como os tubetes de $55 \mathrm{~cm}^{3}$, podem ocasionar deformações no sistema radicular, comprometendo o crescimento inicial das mudas em campo, o que corrobora com os resultados encontrados no presente trabalho.

Dessa forma, no presente trabalho, os tubetes de $55 \mathrm{~cm}^{3}$ não são indicados para produção de mudas de Ceiba speciosa, visto que o melhor indicativo de qualidade de muda é a taxa de sobrevivência e o crescimento inicial no campo (CARNEIRO, 1995). Assim, as mudas produzidas nestas embalagens ficarão com maiores dependências das condições ambientais (precipitação, temperatura máxima e insolação diária), características do solo (principalmente a textura) e declividade do terreno (relacionado à capacidade de armazenamento do solo), do que as produzidas nos recipientes maiores, necessitando de melhores condições para o crescimento satisfatório.

Ainda que as diferenças em altura e diâmetro das mudas implantadas no campo possam diminuir ao logo do tempo (JOSÉ; DAVIDE; OLIVEIRA, 2005; PEZZUTTI; CALDATO, 2011; ABREU et al., 2015; CABREIRA et al., 2017; STEUPP et al., 2017), o melhor desenvolvimento inicial permite que as mudas saiam mais rapidamente da competição com as plantas daninhas, reduzindo os custos de manutenção e implantação dos povoamentos para a restauração florestal (LOPES; AMARAL; NOVAES, 2014; LELES; OLIVEIRA NETO; ALONSO, 2015; RESENDE; LELES, 2017). Dessa forma, as mudas provenientes do tubete de $55 \mathrm{~cm}^{3}$ possuíam menores diâmetros de coleto (Figura 2), não sendo recomendadas para o plantio no campo quando comparadas com os outros tratamentos.

\section{Conclusões}

Utilizando-se o biossólido como principal componente do substrato para a produção das mudas de Ceiba speciosa, e para as condições de sitio em que foi implantado o povoamento florestal, recomenda-se o uso do tubete de $110 \mathrm{~cm}^{3}$, pois neste ocorreu crescimento similar ao das plantas nos tubetes de maior volume, o que resulta em menor volume de substrato e maior facilidade de transporte e manejo.

\section{Referências}

ABREU, A. H. M. Biossólido na produção de mudas florestais. 2014. 96 f. Dissertação (Mestrado em Ciências Ambientais e Florestais) - Universidade Federal Rural do Rio de Janeiro, Seropédica, 2014.

ABREU, A. H. M. et al. Caracterização e potencial de substratos formulados com biossólido na produção de mudas de Schinus terebinthifolius e Handroanthus heptaphyllus. Ciência Florestal, Santa Maria, v. 27, n. 4, p. 1179-1190, 2017a.

ABREU, A. H. M. et al. Characterization of sewage sludge generated in Rio de Janeiro, Brazil, and perspectives for agricultural recycling, Semina: Ciências Agrárias, Londrina, v. 38, n. 4, p. 2433-2448, $2017 \mathrm{~b}$.

ABREU, A. H. M. et al. Produção de mudas e crescimento inicial em campo de Enterolobium contortisiliquum produzidas em diferentes recipientes. Floresta, Curitiba, v. 45, n. 1, p. 141-150, 2015.

AUGUSTO, D. C. C. et al. Utilização de esgotos domésticos tratados através de um sistema biológico na produção de mudas de Croton floribundus Spreng. (capixingui) e Copaifera langsdorffi Desf. (copaíba). Revista Árvore, Viçosa, v. 27, n. 3, p. 335-342, 2003.

BETTIOL, W.; CAMARGO, O. Impacto ambiental do uso agrícola do lodo de esgoto: descrição do estudo. In: BETTIOL, W.; CAMARGO, O. Lodo de esgoto: impactos ambientais na agricultura. Jaguariúna: EMBRAPA Meio Ambiente, 2006. p. 17-24. 
BINOTTO, A. F. et al. Correlations between growth variables and Dickson quality index in forest seedlings. Cerne, Lavras, v. 16, n. 4, p. 457-464, 2010.

BLAISE, D. et al. Effects of farmyard manure and fertilizers on yield, fibre quality and nutrient balance of rainfed cotton (Gossypium hirsutum). Bioresource Technology, Essex, v. 96, p. 345-349, 2005.

BOMFIM, A. A. et al. Avaliação morfológica de mudas de madeira-nova (Pterogyne nitens Tull.) produzidas em tubetes e sacos plásticos e seu desempenho no campo. Floresta, Curitiba, v. 39, n. 1, p. 33-40, 2009.

BOVI, M. L. A. et al. Lodo de esgoto e produção de palmito em pupunheira. Revista Brasileira de Ciência de Solo, Viçosa, v. 31, p. 153-166, 2006.

BRASIL. Ministério de Minas e Energia. Departamento Nacional da Produção Mineral. Projeto RADAM Brasil. Folhas Século 21. Juremo: Geomorfologia, pedologias, vegetação e uso potencial da terra. Brasília: MME, 1980. v. 20. 460 p.

CABREIRA, G. V. et al. Biossólido como componente de substrato para a produção de mudas florestais. Floresta, Curitiba, v. 47, n. 2, p. 165-176, 2017.

CALDEIRA, M. V. W. et al. Composto orgânico na produção de mudas de aroeira vermelha. Scientia Agraria, Curitiba, v. 9, p. 27-33, 2008.

CALDEIRA, M. V. W. et al. Lodo de esgoto e vermiculita na produção de mudas de eucalipto. Pesquisa Agropecuária Tropical, Goiânia, v. 43, n. 2, p. 155-163, 2013a.

CALDEIRA, M. V. W. et al. Substratos alternativos na produção de mudas de Chamaecrista desvauxii. Revista Árvore, Viçosa, v. 37, n. 1, p. 31-39, 2013b.

CARNEIRO, J. G. A. Produção e controle de qualidade de mudas florestais. Curitiba: Campos; UENF; UFPR; FUPEF, 1995. 451 p.

CARVALHO, P. E. R. Espécies arbóreas brasileiras. Colombo: EMBRAPA Florestas, 2004. v. 1. 1039 p.

CUNHA, A. C. M. C. M. et al. Papel da nutrição mineral na formação de raízes adventícias em plantas lenhosas. Pesquisa Florestal Brasileira, Colombo, n. 58, p. 35-47, 2009.

CUNHA, A. O. et al. Efeitos de substratos e das dimensões dos recipientes na qualidade das mudas de Tabebuia impetiginosa (Mart. ExD.C.) Standl. Revista Árvore, Viçosa, MG, v. 29, n. 4, p. $507-$ $516,2005$.

DAVIDE, A. C.; SILVA, E. A. A. Produção de sementes e mudas de espécies florestais. Lavras: Editora da UFLA, 2008. $128 \mathrm{p}$.

DICKSON, A.; LEAF, A. L.; HOSNER, J. F. Quality appraisal of white spruce and white pine seedling stock in nurseries. Forest Chronicle, Toronto, v. 36, p. 10-13,1960.

FERRAZ, A. V.; ENGEL, V. L. Efeito do tamanho de tubetes na qualidade de mudas de jatobá (Hymenaea courbaril L. var. stilbocarpa (Hayne) Lee et Lang.), ipê-amarela (Tabebuia chrysotricha (Mart. ex Dc.) Sandl.) e guarucaia (Parapiptadenia rigida (Benth.) Brenan). Revista Árvore, Viçosa, v. 35, n. 3, p. 413-423, 2011.

FREITAS, T. A. S. et al. Outplanting performance of eucalyptus clonal cuttings produced in different containers and substrates. Revista Árvore, Viçosa, v. 32, n. 6, p. 1019-1028, 2008.

GASPARIN, E. et al. Influência do substrato e do volume de recipiente na qualidade das mudas de Cabralea canjarana (Vell.) Mart. em viveiro e no campo. Ciência Florestal, Santa Maria, v. 24, n. 3, p. 553-563, 2014.

GOMES, D. R. et al. Lodo de esgoto como substrato para a produção de mudas de Tectona grandis L.

Cerne, Lavras, v. 19, n. 1, p. 123-131, 2013. 
GOMES, J. M. et al. Influência do tamanho da embalagem plástica na produção de mudas de ipê (Tabebuia serratifolia) de copaíba (Copaifera langsdorffii) e de angico-vermelho (Piptadenia peregrina). Revista Árvore, Viçosa, v. 14, n. 1, p. 26-34, 1990.

GOMES, J. M. et al. Parâmetros morfológicos na avaliação da qualidade de mudas de Eucalyptus grandis. Revista Árvore, Viçosa, v. 26, n. 6, p. 655-664, 2002.

GONÇALVES, E. O. et al. Nutrição de mudas de angico-vermelho (Anadenanthera macrocarpa (Benth.) Brenan) submetidas a doses de N, P, K, Ca e Mg. Revista Árvore, Viçosa, v. 36, n. 2, p. 219-228, 2012.

GONÇALVES, J. L. M. et al. Produção de mudas de espécies nativas: substrato, nutrição, sombreamento e fertilização. In: GONÇALVES, J. L. M.; BENEDETTI, V. Nutrição e fertilização florestal. Piracicaba: Instituto de Pesquisa Florestal, 2000. p. 309-350.

GONÇALVES, J. L. M. Recomendações de adubação para Eucalyptus, Pinus e espécies típicas da Mata Atlântica. Piracicaba: ESALQ, 1995. (Série Documentos Florestais, 15).

INSTITUTO NACIONAL DE METEOROLOGIA. Precipitação diária tempertaura máxima Cordeiro, RJ. Brasília: INMET, [2014]. Disponível em: http://www.inmet.gov.br/html/observacoes.php?. Acesso em: 15 jul. 2014.

JOSÉ, A. C.; DAVIDE, A. C.; OLIVEIRA, S. L. Produção de mudas de aroeira (Schinus terebinthifolius Raddi) para recuperação de áreas degradadas pela mineração de bauxita. Cerne, Lavras, v. 11, n. 12, p. 187-196, 2005.

KELLER, L. et al. Sistemas de blocos prensados para produção de mudas de três espécies arbóreas nativas. Revista árvore, Viçosa, v. 33, n. 2, p. 305-314, 2009.

LAMHAMEDI, M. S. et al. Physiological and growth responses of three sizes of containerized Picea mariana seedlings outplanted with and without vegetation control. Forest Ecology and Management, Amsterdam, v. 110, n. 1/3, p. 13-23, 1998.

LELES, P. S. S.; OLIVEIRA NETO, S. N.; ALONSO, J. M. Restauração florestal em diferentes espaçamentos. In: LELES, P. S. S.; OLIVEIRA NETO, S. N. (Ed.). Restauração florestal e a Bacia do Rio Guandu. Seropédica: Editora da UFRRJ, 2015, p. 101-153.

LISBOA, A. C. et al. Efeito do volume de tubetes na produção de mudas de Calophyllum brasiliense e Toona ciliata. Revista Árvore, Viçosa, v. 36, n. 4, p. 603-609, 2012.

LOPES, E. D.; AMARAL, C. L. F.; NOVAES, A. B. Desempenho no campo de mudas de Eucalyptus urophylla, Eucalyptus camaldulensis e Corymbia citriodora produzidas em diferentes recipientes. Floresta, Curitiba, v. 44, n. 4, p. 589-596, 2014.

LORENZI, H. Árvores brasileiras: manual de identificação e cultivo de plantas nativas do Brasil. 6. ed. Nova Odessa: Instituto Plantarum, 2014. 368 p.

MALAVASI, U. C.; MALAVASI, M. M. Efeito do volume do tubete no crescimento inicial de plântulas de Cordia trichotoma (Vell.) Arrab. ex Steud e Jacaranda micranta Cham. Ciência Florestal, Santa Maria, v. 16, n. 1, p. 11-16, 2006.

MEXAL, J. G. et al. Nursery production practices affect survival and growth of tropical hardwoods in Quintana Roo, Mexico. Forest Ecology and Management, Amsterdam, v. 168, n. 2, p. 125-133, 2002.

NEVES, C. S. V. J. et al. Efeitos de substratos e recipientes utilizados na produção das mudas sobre a arquitetura do sistema radicular de árvores de acácia-negra. Revista Árvore, Viçosa, v. 29, n. 6, p. $897-905,2005$.

NICOLOSO, F. T. et al. Recipientes e substratos na produção de mudas de Muytenus ilicifolia e Apuleia leiocarpa. Ciência Rural, Santa Maria, v. 30, n. 6, p. 987-992, 2000.

NOBREGA, R. S. A. et al. Utilização de biossólido no crescimento inicial de mudas de aroeira (Schinus terebynthifolius Raddi). Revista Árvore, Viçosa, v. 31, n.2, p. 239-246, 2007. 
NOVAES, A. B. et al. Avaliação do potencial de regeneração de raízes de mudas de Pinus taeda L., produzidas em diferentes tipos de recipientes, e o seu desempenho no campo. Revista Árvore, Viçosa, v. 26, n. 6, p. 675-681, 2002.

PADOVANI, V. C. R. Composto de lodo de esgoto como substrato para produção de mudas de árvores nativas e exóticas. 2006. 81 f. Dissertação (Mestrado em Engenharia Agrícola) - Universidade Estadual de Campinas, Campinas, 2006.

PEZZUTTI, R. V.; CALDATO, S. L. Sobrevivência e crescimento inicial de mudas de Pinus taeda L. com diferentes diâmetros de coleto. Ciência Florestal, Santa Maria, v. 21, n. 2, p. 355-362, 2011.

PORTELA, R. C. Q.; SILVA, I. L.; PINÃ-RODRIGUES, F. C. M. Crescimento inicial de mudas de Clitoria fairchildiana Howard e Peltophorum dubium (Sprenge) Taub em diferentes condições de sombreamento. Ciência Florestal, Santa Maria, v. 11, n. 2, p. 163-170, 2001.

QUINTANA, N. R. G.; CARMO, M. S.; MELO, W. J. Valor agregado ao lodo de esgoto. Revista Energia na Agricultura, Botucatu, v. 24, n. 1, p. 121-129, 2009.

RESENDE, A. S.; LELES, P. S. S. (Ed.). Controle de plantas daninhas em restauração florestal. Brasília: EMBRAPA, 2017. 107 p.

RIO DE JANEIRO. Secretaria de Estado do Ambiente. Diagnóstico da produção de mudas de espécies nativas no Estado do Rio de Janeiro. 1. ed. Rio de Janeiro: SEA, 2010. 63 p.

RITCHIE, G. A. et al. Assessing plant quality. In: LANDIS, T. D.; DUMROESE, R. K.; HAASE, D. L. Seedling processing, storage, and outplanting. Washington: U.S. Department of Agriculture Forest Service, 2010. v. 7. p. 17-82.

RODRIGUES, R. R.; BRANCALION, P. H. S.; ISERNHAGEN, I. (Ed.). Pacto pela restauração da Mata Atlântica - Referencial dos conceitos e ações de restauração florestal. São Paulo: LERF, 2009. 259 p.

SANTOS, C. B. et al. A Efeito do volume de tubetes e tipos de substratos na qualidade de mudas de Cryptomeria japonica (L. f.) D. Don. Ciência Florestal, Santa Maria, v. 10, n. 2, p. 1-15, 2000.

SANTOS, F. E. V. Caracterização física e química de substratos com lodo de esgoto na produção de mudas de Aegiphila sellowiana Cham. 2013. 151f. Dissertação (Mestrado em Ciências Florestais) Universidade Federal do Espírito Santo, Jerônimo Monteiro, 2013.

STUEPP, C. A. et al. Clonal forestry of Piptocarpha angustifolia: survival and growth vigorin fild conditions. Cerne, Lavras, v. 23, n. 1, p. 69-74, 2017.

TEIXEIRA, S. A. et al. Efeito de diferentes tamanhos de sacos plástico, na produção de mudas de Triplaris americana L. e Jacaranda micrantha Cham. Revista Brasileira de Biociências, Porto Alegre, v. 5, n. 4, p. 765-767, 2005.

TRAZZI, P. A. et al. Qualidade de mudas de Murraya paniculata produzidas em diferentes substratos. Floresta, Curitiba, v. 42, n. 3, p. 621-630, 2012.

VIANA, J. S. et al. Crescimento de mudas de Bauhinia forficata Link. em diferentes tamanhos de recipientes. Floresta, Curitiba, v. 38, n. 4, p. 663-671, 2008.

ZONTA, E. et al. O sistema radicular e suas interações com o ambiente edáfico. In: FERNANDES, M. S. (Ed.). Nutrição mineral de plantas. Viçosa: Sociedade Brasileira de Ciência do Solo, 2006. p. 7-52. 